\title{
Five Years Facts of Bladder Cancer at West Java's Top Referral Hospital, in Indonesia
}

\author{
Vivien Kate Perix, ${ }^{1}$ Sri Suryanti, ${ }^{2}$ Aaron Tigor Sihombing ${ }^{3}$ \\ ${ }^{1}$ Faculty of Medicine Universitas Padjadjaran, ${ }^{2}$ Department of Anatomical Pathology Faculty of \\ Medicine Universitas Padjadjaran/Dr. Hasan Sadikin General Hospital Bandung, ${ }^{3}$ Department \\ of Surgery Faculty of Medicine Universitas Padjadjaran/Dr. Hasan Sadikin General Hospital \\ Bandung
}

\begin{abstract}
Background: Bladder cancer is the second most common genitourinary cancer and its incidence is rising $15 \%$ annually in Indonesia. Smoking is the leading risk factor of bladder cancer and two thirds of men in Indonesia smokes. This study was conducted to describe the characteristics of bladder cancer based on sex, age and histopathology type in West Java's Top Referral Hospital, Indonesia.

Methods: This study was a descriptive study conducted during theperiod of September to November 2015 using 372 histopathological medical records of patients who had primary and secondary bladder cancer at the Pathology Department, Dr. Hasan Sadikin General Hospital Bandung from January 2010 to December 2014. Data were collected using total sampling method based on the characteristics of age, sex histopathology type, and staging of bladder cancer.

Results: Out of the 372 cases, 298 cases were male and 38 cases were female with a male to female ratio of 7.8:1. The age group with the highest incidence was the 50-59 years old group. Infiltrating urothelial carcinoma was the most common histopathology type $(71.1 \%)$ in primary cancers, $66.1 \%$ of cases was muscle invasive while $33.9 \%$ was non muscle invasive. Staging pT1 had the most number of cases. The most common site of origin for secondary neoplasm was cervix with adenocarcinoma as the most common histopathology type.

Conclusions: Bladder cancer is more common in male than female and peaks at the sixth decade of life. Infiltrating urothelial carcinoma is the most common histopathology type. [AMJ.2017;4(1):94-9]
\end{abstract}

Keywords: Age, bladder cancer, histopathology type, sex

\section{Introduction}

Bladder cancer is the second most common genitourinary cancer and accounts for $3.2 \%$ of the total cancer cases worldwide. ${ }^{1}$ Based on Globocan Data 2012, the incidence of bladder cancer patients in Indonesia for both sexes is 3.2 per $100,000{ }^{1}$ This incidence is increasing $15 \%$ per annum in the last decade in Indonesia. ${ }^{2}$ The mortality rate is 1.7 per 100,000 cases. $^{1}$ Bladder cancer is three times more common in male than female. ${ }^{3}$ However, in women, the disease has a higher mortality and presents in a more advanced stage. ${ }^{4}$ The peak of bladder cancer is in the sixth or seventh decade. 3 The most common histopathology type is Infiltrating Urothelial Carcinoma. ${ }^{2}$

The most important risk factor for bladder cancer is smoking. ${ }^{5}$ Two thirds of the Indonesian population of male smokes and West Java has the second highest number of smokers in Indonesia. ${ }^{6}$ Occupation exposure for example azo dyes used in textile industries is also associated with elevated bladder cancer risk. West Java accounts for the highest clothing production in Indonesia. The increasing number of smokers and exposure to occupational carcinogens along with the increasing geriatric population in West Java will increase the incidence of bladder cancer in West Java, in addition increasing the burden of cancer in Indonesia.

Based on the factors above and the differences in genetic composition in Indonesians, the objective of the study was to describe the characteristics of patients

Correspondence: Vivien Kate Perix, Faculty of Medicine, Universitas Padjadjaran, Jalan Raya Bandung-Sumedang Km.21, Jatinangor, Sumedang, Indonesia, Phone: +62 81802265201 Email: vperix@gmail.com 
with bladder cancer based on age, sex and histopathology type at Dr. Hasan Sadikin General Hospital Bandung as West Java's Top Referral Hospital from January 2010 to December 2014.

\section{Methods}

This was a descriptive study of all primary and secondary bladder cancer cases from 1st January 2010 to 31st December 2014 (5 Years) that were collected from the Pathology Department at Dr. Hasan Sadikin General Hospital Bandung. This study was carried out during 6 months from July to December 2015 using medical records. The inclusion criteria of the study were histopathological medical records of patients who were diagnosed with bladder cancer comprising the age, sex and histopathology type. Data was excluded if the medical records were not complete or unclear. From 381 cases of bladder cancer during the period, nine cases were excluded. The total sampling method was used to obtain the samples.

Bladder tumours were classified histopathologically according to the World
Health Organization (WHO)/International Society of Urological Pathology consensus classification 2004 which classified thetumours into urothelial tumours, squamous neoplasms, glandular neoplasms, neuroendocrine tumours, melanocytic tumours, mesenchymal tumours, haematopoietic and lymphoid tumours. ${ }^{7}$ Pathological staging was specified according to TMN system with the following stages, pT1: invasion of lamina propria, pT2: invasion of muscularis propria, pT3: invasion of perivesical fat and pT4: invasion of surrounding organs. ${ }^{7}$ The data was presented in frequency distribution. Ethical clearence was given by the Health Research Ethics Committee of Dr. Hasan Sadikin General Hospital.

\section{Results}

The total number of bladder cancer cases recorded at the Department of Anantomical Pathology in Dr. Hasan Sadikin General Hospital Bandung was 372 cases, consisting of 336 cases of primary bladder cancer and 36 cases of secondary bladder cancer.

Table 1 Frequency of Bladder Cancer Patients Based on Year

\begin{tabular}{lccc}
\hline Year & $\begin{array}{c}\text { Total Malignant Tumor Cases } \\
\text { in Dr. Hasan Sadikin General } \\
\text { Hospital }\end{array}$ & Bladder Cancer & \% \\
\hline 2010 & 4,695 & 66 & 1.41 \\
2011 & 3,476 & 71 & 2.04 \\
2012 & 3,662 & 57 & 1.56 \\
2013 & 3,468 & 93 & 2.71 \\
2014 & 3,206 & 85 & 2.68 \\
Total & 18,507 & 372 & 2.02 \\
\hline
\end{tabular}

Table 2 Characteristics of Primary Bladder Cancer Patients Based on Age and Sex

\begin{tabular}{|c|c|c|c|c|}
\hline \multirow{2}{*}{ Age in years } & \multicolumn{2}{|c|}{ Sex } & \multirow{2}{*}{ Number of cases } & \multirow{2}{*}{$\%$} \\
\hline & Male & Female & & \\
\hline$<40$ & 30 & 1 & 31 & 9.2 \\
\hline $40-49$ & 32 & 6 & 38 & 11.3 \\
\hline $50-59$ & 94 & 11 & 105 & 31.3 \\
\hline $60-69$ & 65 & 7 & 72 & 21.4 \\
\hline $70-79$ & 64 & 12 & 76 & 22.6 \\
\hline $80-89$ & 13 & 1 & 14 & 4.2 \\
\hline Total & 298 & 38 & 336 & 100.0 \\
\hline
\end{tabular}


Table 3 Characteristics Primary Bladder Cancer Patients Based on Histopathology Type According to WHO Classification 2004

\begin{tabular}{lcc}
\hline \multicolumn{1}{c}{ Histopathology Type } & $\begin{array}{c}\text { Number of } \\
\text { cases }\end{array}$ & \% \\
\hline Invasive urothelial neoplasias & & \\
$\quad$ Infiltrating urothelial carcinoma & 239 & 71.1 \\
Non-invasive urothelial neoplasias & & \\
$\quad$ Non invasive papillary urothelial neoplasm of low malignant potential & 26 & 7.7 \\
$\quad$ Non invasive papillary urothelial carcinoma, low grade & 20 & 6.0 \\
$\quad$ Non invasive papillary urothelial carcinoma, high grade & 5 & 1.5 \\
Squamous cell carcinom & 21 & 6.3 \\
Adenocarcinoma & 18 & 5.3 \\
Rhabdomyosarcoma & 7 & 2.1 \\
Total & 336 & 100.0 \\
\hline
\end{tabular}

The highest number of cases and frequency recorded was in year 2013, followed by year 2014. The least number of cases was found in year 2012, however the lowest frequency was found in year 2010 (Table 1).

The incidence of bladder cancer was higher in men $(88.7 \%)$ compared to women $(11.3 \%)$ with the male to female ratio was 7.8:1. For male the highest incidence was found in the age group 50-59 years while in female, the highest incidence was in the age group 50-59 years and 70-79 years. The oldest age reported was 87 years with histopathological type infiltrating urothelial carcinoma. The youngest age reported was 9 years old with histopathological type rhabdomyosarcoma (Table 2).

The most common histopathology type was urothelial neoplasias, which was divided into invasive $(71.1 \%)$ and non invasive neoplasias $(15.2 \%)$. In this study, the invasive urothelial neoplasia, infiltrating urothelial carcinoma had the highest percentage of cases. The next most common histopathology type was squamous cell carcinoma which constituted $6.3 \%$ of the total cases, followed by adenocarcinoma (5.3\%). The least common histopathology type was rhabdomyosarcoma (2.1\%) (Table 3).

The invasive urothelial carcinoma that invaded the lamina propria, pT1 (66.1\%) was the most common staging reported followed by pT $4(22.2 \%)$. The least common staging was pT3 $(2.09 \%)$, that had invaded the perivesical fat. $33.9 \%$ of the patients had muscle- invasive disease at the time of the presentation while the remaining $66.1 \%$ had non muscle-invasive disease (pT1) (Table 4).

There was a total of 36 secondary bladder cancer cases, $63.9 \%$ of the cases were female while $36.1 \%$ of the cases were male with a male to female ratio of $0.6: 1$. The most common age group was 40-49 years old. The most common

Table 4 Pathologic Staging of Infiltrating Urothelial CarcinomaAccording to WHO Classification 2004 Based on Sex

\begin{tabular}{lccccc}
\hline \multirow{2}{*}{ Stage } & \multicolumn{3}{c}{ Sex } & \multirow{2}{*}{ Total } & \% \\
\cline { 2 - 4 } & Male & Female & & 66.1 \\
pT1 & 141 & 17 & 158 & 9.6 \\
pT2 & 22 & 1 & 23 & 2.1 \\
pT3 & 5 & 0 & 5 & 22.2 \\
pT4 & 51 & 2 & 53 & 100.0 \\
Total & 219 & 20 & 239 & \\
\hline
\end{tabular}


Table 5 Characteristics of Secondary Bladder Cancer

\begin{tabular}{lc}
\hline \multicolumn{1}{c}{ Characteristics } & Number of cases \\
\hline Sex & 13 \\
Male & 23 \\
Female & $0.6: 1$ \\
Male to female ratio & \\
Age (years) & 7 \\
$<40$ & 12 \\
$40-49$ & 11 \\
$50-59$ & 5 \\
$60-69$ & 1 \\
$70-79$ & 0 \\
$80-89$ & \\
Histopathology type & 13 \\
Adenocarcinoma & 7 \\
Squamous cell carcinoma & 1 \\
Rhadmonyosarcoma & 15 \\
Not specified & \\
Origin & 19 \\
Cervix & 5 \\
Prostate & 3 \\
Ovarian & 3 \\
Colon & 2 \\
Rectum & 2 \\
Intra abdomen & 1 \\
Vulva & \\
Ileum & \\
\hline
\end{tabular}

histopathology type was adenocarcinoma (36.1\%). The least common histopathology type was rhabdomyosarcoma $(2.8 \%)$. Cervix was the most common site of origin for secondary bladder cancer accounting for $52.8 \%$ of the cases, followed by prostate (13.9\%). The least common site of origin was intra abdomen, vulva and ileum (Table 5).

\section{Discussion}

In this study, the incidence of bladder cancer was higher in men than women, with the male to female ratio of $7.8: 1$. This ratio is comparable to previous studies in India3 (8.6:1) and Malaysia ${ }^{8}$ (9.4:1) but was higher than other studies conducted in Surabaya, Indonesia ${ }^{9}$ and $\mathrm{Nepal}^{10}$ with ratio of 3-4:1. The higher incidence in men may be attributed to the higher exposure to carcinogens as smoking is the leading risk factor of bladder cancer and West Java has the second highest number of smokers aged more than 10 in Indonesia. ${ }^{6}$ The lower incidence in female may be attributed to the decreased exposure to carcinogens from cigarettes in addition to less occupational exposure as less number of women work outside their homes.

The mean age of diagnosis in this study was 58.5 which is similar to other studies in North India $^{11}$ (59.0) and Indonesia ${ }^{9}$ (57.8). In this study, $79.5 \%$ of the patients were older than 50 years and this was similar as reported in North India ${ }^{11}$ which was $83.7 \%$. Overall, the highest incidence was in the age group 5059 years. This is similar to a previous study in Surabaya, Indonesia. ${ }^{9}$ In male, the highest incidence was in the age group 50-59 years while in female, the incidence peaks at the age group 50-59 years and 70-79 years. A study in Nepal ${ }^{10}$ and North India ${ }^{11}$ showed an older age group for male, 61-70 years as the peak age group, while the peak age group for female were similar, $51-60$ years and $71-80$ years. $^{10}$ The lower peak incidence age group of men in Indonesia is linked to the higher number of smokers who start smoking at a younger age of 10 years which increases the exposure of carcinogens at an earlier age.

Infiltrating urothelial carcinoma was the most common histopathology type in this study. This is coherent with other studies which reported similar findings of infiltrating urothelial carcinoma being the most common type, however the percentage in this study was much lower than reported in other studies. ${ }^{3,8,10,11}$ Squamous cell carcinoma prevalence varies in different parts of the world and is higher in Egypt $^{8}$ where schistosomiasis is endemic. In this study the prevalence was $5.4 \%$ which is comparable to the study in $\mathrm{Nepal}^{10}$ but was much higher than reported in the study conducted in Malaysia ${ }^{8}(1.2 \%)$ and North India ${ }^{11}(2.5 \%)$. The histopathology type adenocarcinoma was accounted for $5.6 \%$ of the total cases and is similar to the study in Malaysia $^{8}(6.0 \%)$ but studies in $\mathrm{Nepal}^{12}$ and India $^{3}$ showed a lower percentage of $0.93 \%$ and $1.25 \%$ respectively.

Numerous studies have been published to show the survival rate differences between invasive and non-invasive tumours. In this study, the urothelial tumors which were invasive was $82.4 \%$ while the non-invasive 
urothelial tumours was $17.6 \%$. The percentage of non-invasive tumours reported is much lower than the previous study conducted in Malaysia. ${ }^{8}$

In terms of age, young people tend to develop more non-invasive urothelial tumours rather invasive urothelial tumours and this is the characteristic of bladder cancer that differentiates it from other cancers where younger people develop more aggressive forms of the disease. However in this study, there was a higher percentage of invasive urothelial tumours in young people compared to non-invasive tumours. This is different from the studies in Taipei ${ }^{13}$ and Greece ${ }^{14}$ where there are more non-invasive tumours than invasive tumours at time of presentation in younger people.

In this study, $33.9 \%$ of the patients had muscle-invasive disease at the time of the presentation while the remaining $66.1 \%$ had non muscle-invasive disease. This is different from other previous studies where there is a higher percentage of muscle invasive rather than non muscle-invasive disease..$^{10}$ In this study, women had less invasive and less aggressive form of the disease and is thus similar to a previous study in Austria. ${ }^{15}$ This is opposing to other previous studies conducted in India and Nepal which stated that women have more invasive and more aggressive form of disease at time of diagnosis. ${ }^{3,10,12}$ The less aggressive and less invasive form of bladder cancer in women as reported in this study, attributed to the prompt diagnosis by clinicians when presenting symptoms occurred.

Secondary cancers that invade or infiltrate the bladder are very rare. In this study, there were only 36 cases reported in the period of 5 years and accounts for $9.7 \%$ of the total bladder cancer cases. In a previous study, it was reported that secondary bladder neoplasm represents $2 \%$ of the total malignant bladder neoplasm. ${ }^{16}$ The percentage of secondary tumours in this current study was much higher than the previous study. The most common histopathology type of secondary bladder cancers reported was adenocarcinoma (36.1\%). Since adenocarcinomas are rare in primary bladder neoplasm, when an adenocarcinoma histopathology type is found, the pathologist should carry out further investigation of possible metastasis of other origin as the presence of adenocarcinomas was high in secondary neoplasms in this study. Some tumors of histopathology type were not specified, because more immunohistochemical workup is needed to identify the tumours that are present with less histological characteristics. ${ }^{7}$ In this study, the most common sites of origin in secondary bladder neoplasms were the cervix in female and prostat in male. In previous studies, the most common site of origin is from colonic carcinomas, prostate, rectum and uterine cervix..$^{7,17}$

From this study, it can be concluded that bladder cancer is more common in male than female. Bladder cancer peaks at the $6^{\text {th }}$ decade for male while in female, it peaks at the $6^{\text {th }}$ and $8^{\text {th }}$ decade. Infiltrating urothelial carcinoma is the most common histopathology type overall while rhabdomyosarcoma is the most uncommon histopathology type in primary bladder cancers. There are more non muscles invasive tumours (stage pT1) present. The most common site of metastasis to the bladder is the cervix in female and prostate in male.

The limitation of this study is that there were many missing medical records as they were not stored in electronic form. Future efforts must focus on analyzing the significance between bladder cancer and smoking as its main risk factor in West Java. The high number of bladder cancer cases in male in their 50's indicates a need for screening for bladder cancer to ensure better care and less mortality rate.

\section{References}

1. Ferlay J, Soerjomataram I, Ervik M, Dikshit R, Eser S, Mathers C, et.al. GLOBOCAN 2012Cancer incidence and mortality worldwide. International Agency for Research on Cancer2013. [cited 2015 May 20]. Available from: http://globocan.iarc. fr.

2. Wempy Supit, Chaidir A Mochtar, Marto Sugiono, Rainy Umbas. Survival of patients with transitional cell carcinoma of the urinary bladder in Indonesia: a single institution review. Asian Pac J Cancer Prev. 2011;12(2):549-53.

3. Gupta P, Jain M, Kapoor R, Muruganandham K, Srivastava A, Mandhani A. Impact of age and gender on the clinicopathological characteristics of bladder cancer. Indian J Urol. 2009;25(2):207-10.

4. Fajkovic H, Halpern JA, Cha EK, Bahadori A, ChromeckiTF, Karakiewicz PI, et al. Impact of gender on bladder cancer incidence, staging, and prognosis. World J Urol. 2011;29(4):457-63.

5. Freedman ND, Silverman DT, Hollenbeck AR, Schatzkin A, Abnet CC. Association between smoking and risk of bladder 
cancer among men and women. JAMA. 2011;306(7):737-45.

6. Kementerian Kesehatan Republik Indonesia. Riset Kesehatan Dasar (Riskesdas) 2013. Jakarta: Badan Penelitian dan Pengembangan Kesehatan Kementerian Kesehatan Republik Indonesia; 2013.

7. Eble J, Sauter G, Epstein J, Sesterhenn I,editors. Pathology and genetics of tumours of the urinary system and male genital organs. Lyon: IARC Press; 2004.

8. Kong CHC, Singam P, Hong GE, Cheok LB, Azrif M, Tamil AM, et al. Clinicopathological features of bladder tumours in a single institution in Malaysia. Asian Pac J Cancer Prev. 2010;11(1):149-52.

9. Asro Abdih, Wahjoe Djatisoesanto, Sunaryo Hardjowijoto. Profile of bladder transitional cell cancer in Soetomo Hospital Surabaya.JURI. 2014;21(2):1-6.

10. Joshi HN, Makaju R, Karmacharya A, Karmacharya RM, Shrestha B, Shrestha $\mathrm{R}$, et al. Urinary bladder carcinoma: impact of smoking, age and its clinicopathological spectrum.Kathmandu Univ Med J.2013;4(44):292-5.

11. BeniwalK,GoelS,RanaP.Clinicopathological analysis of urinary bladder tumors at a tertiary care institute in North India. Int J Sci Stud. 2015;12(2):96-9.

12. Vaidya S, Lakhey M, Sabira K, Hirachand
S. Urothelial tumours of the urinary bladder: a histopathological study of cystoscopic biopsies. J Nepal Med Assoc. 2013;52(191):475-78.

13. Wen Y-C, Kuo J-Y, Chen K-K, Lin AT, Chang $\mathrm{Y}-\mathrm{H}, \mathrm{Hsu} \mathrm{Y}-\mathrm{S}$, et al. Urothelial carcinoma of the urinary bladder in young adultsclinical experience at Taipei Veterans General Hospital. J Chin Med Assoc. 2005;68(6):272-5.

14. Nomikos M, Pappas A, Kopaka M-E, Tzoulakis S, Volonakis I, Stavrakakis G, et al. Urothelial carcinoma of the urinary bladder in young adults: presentation, clinical behavior and outcome. Adv Urol. 2011;2011(1):1-4.

15. Horstmann M, Witthuhn R, Falk M, Stenzl A. Gender-specific differences in bladder cancer: a retrospective analysis. Gend Med. 2008;5(4):385-94.

16. András C, Tóth L, Pósán J, Csiki E, Tanyi M, Csiki Z, et al. Occurrence of bladder metastasis 10 years after surgical removal of a primary gastric cancer: a case report and review of the literature. J Med Case Rep. 2013;7(204):1-4.

17. Morichetti D, Mazzucchelli R, LopezBeltran A, Cheng L, Scarpelli M, Kirkali Z, et al. Secondary neoplasms of the urinary system and male genital organs. BJU Int. 2009;104(6):770-6. 